\title{
The involvement of TRPC3 channels in sinoatrial arrhythmias
}

\author{
Yue-Kun Ju ${ }^{1 *}$, Bon Hyang Lee ${ }^{1}$, Sofie Trajanovska ${ }^{1}$, Gouliang Hao ${ }^{2}$, David G. Allen ${ }^{1 *}$, \\ Ming Lei ${ }^{2}$ and Mark B. Cannell ${ }^{3 *}$ \\ 'Department of Physiology, School of Medical Sciences, Bosch Institute, University of Sydney, Sydney, NSW, Australia, \\ ${ }^{2}$ Department of Pharmacology, University of Oxford, Oxford, UK, ${ }^{3}$ Department of Physiology and Pharmacology, \\ University of Bristol, Bristol, UK
}

\section{OPEN ACCESS}

Edited by:

Christopher Huang,

University of Cambridge, UK

Reviewed by:

Steve Poelzing

Virginia Tech, USA

Thomas Hund

Ohio State University, USA

${ }^{*}$ Correspondence:

Yue-kun Ju and David G. Allen,

Department of Physiology,

School of Medical Sciences (F13),

University of Sydney, Anderson Stuart

Building, Eastern Ave.,

Sydney, NSW 2006, Australia

yue-kun.ju@sydney.edu.au;

david.allen@sydney.edu.au;

Mark B. Cannell,

Department of Physiology and Pharmacology, University of Bristol, Medical Sciences Building, University Walk, Bristol BS8 1TD, UK

mark.cannel/@bristol.ac.uk

Specialty section:

This article was submitted to Cardiac

Electrophysiology, a section of the

journal Frontiers in Physiology

Received: 28 November 2014 Accepted: 04 March 2015 Published: 25 March 2015

Citation:

Ju Y-K, Lee BH, Trajanovska S, Hao G, Allen DG, Lei M and Cannell MB (2015) The involvement of TRPC3 channels in sinoatrial arrhythmias.

Front. Physiol. 6:86

doi: 10.3389/fphys.2015.00086
Atrial fibrillation (AF) is a significant contributor to cardiovascular morbidity and mortality. The currently available treatments are limited and AF continues to be a major clinical challenge. Clinical studies have shown that $A F$ is frequently associated with dysfunction in the sino-atrial node (SAN). The association between AF and SAN dysfunction is probably related to the communication between the SAN and the surrounding atrial cells that form the SAN-atrial pacemaker complex and/or pathological processes that affect both the SAN and atrial simultaneously. Recent evidence suggests that $\mathrm{Ca}^{2+}$ entry through TRPC3 (Transient Receptor Potential Canonical-3) channels may underlie several pathophysiological conditions -including cardiac arrhythmias. However, it is still not known if atrial and sinoatrial node cells are also involved. In this article we will first briefly review TRPC3 and $\mathrm{IP}_{3} \mathrm{R}$ signaling that relate to store/receptor-operated $\mathrm{Ca}^{2+}$ entry (SOCE/ROCE) mechanisms and cardiac arrhythmias. We will then present some of our recent research progress in this field. Our experiments results suggest that pacing-induced AF in angiotensin II (Ang II) treated mice are significantly reduced in mice lacking the TRPC3 gene (TRPC3 ${ }^{-/-}$mice) compared to wild type controls. We also show that pacemaker cells express TRPC3 and several other molecular components related to SOCE/ROCE signaling, including STIM1 and IP ${ }_{3}$ R. Activation of G-protein coupled receptors (GPCRs) signaling that is able to modulate SOCE/ROCE and Ang II induced $\mathrm{Ca}^{2+}$ homeostasis changes in sinoatrial complex being linked to TRPC3. The results provide new evidence that TRPC3 may play a role in sinoatrial and atrial arrhythmias that are caused by GPCRs activation.

\section{Keywords: TRPC3, receptor-operated $\mathrm{Ca}^{2+}$ entry, store-operated $\mathrm{Ca}^{2+}$ entry, arrhythmias, sinoatrial node}

\section{Introduction}

\section{The Role of Intracellular $\mathrm{Ca}^{2+}$ in Sinoatrial Arrhythmias}

In the normal heart, pacemaker cells in the sinoatrial node (SAN) generate spontaneous membrane depolarizations that trigger action potentials, which then propagate through the conduction system to initiate atrial and ventricular cell depolarization and contraction. In contrast to normal pacemaker activity, abnormal arrhythmogenic electrical activity can arise in ectopic sites due to impulse re-entry or abnormal spontaneous membrane depolarizations (Nattel, 2002).

SAN and the surrounding atria form the SAN-Atrial pacemaker complex, which can provide substrates for re-entrant activity that can lead to AF (Sanders et al., 2004; Fedorov et al., 2010). 
Dysfunction of pacemaker ion channels, including altered HCN4 channels, are associated with familial tachycardia-bradycardia syndrome and atrial fibrillation (Duhme et al., 2013). While it is clear that cardiac arrhythmias, including SAN dysfunction and atrial fibrillation (AF), are multifactorial there is increasing experimental evidence for abnormal $\mathrm{Ca}^{2+}$ handling being a key factor (Dobrev and Nattel, 2008; Yeh et al., 2008) and is the focus of this paper.

The most prominent $\mathrm{Ca}^{2+}$-dependent ionic current during pacemaker activity is the $\mathrm{Na} / \mathrm{Ca}$ exchange (NCX) current which not only contributes to pacemaker current(s) but may also produce arrhythmogenic electrical activity (Sipido et al., 2006) which is related to abnormalities in $\mathrm{Ca}^{2+}$ handling leading to abnormal NCX currents (Hove-Madsen et al., 2004; Vest et al., 2005). Spontaneous $\mathrm{Ca}^{2+}$ release events or "leak" via the ryanodine receptor (RyR), the major cardiac $\mathrm{SR} \mathrm{Ca}^{2+}$ release channel, will produce depolarizing NCX current and contribute spontaneous membrane depolarization(s) to feed the genesis of AF (for review see Greiser et al., 2011; Wakili et al., 2011). In addition, AF has also been linked to $\mathrm{Ca}^{2+}$ release via a second class of SR $\mathrm{Ca}^{2+}$ release channel, inositol 1,4,5-trisphosphate receptor family ( $\mathrm{IP}_{3} \mathrm{Rs}$ ) (Woodcock et al., 2000; Mackenzie et al., 2002; Li et al., 2005; Berridge, 2009). Activation of $\mathrm{IP}_{3} \mathrm{Rs}$ by $\mathrm{IP}_{3}$ is linked to the activation of G-protein coupled receptors (GPCRs) and the phospholipase C (PLC)- $\mathrm{IP}_{3}$ signaling pathway (see Figure 1). Activation of GPCRs by agonists such as angiotensin II (Ang II) or endothelin-1 (ET-1) can cause SAN dysfunction (Neef et al., 2010) and AF (Woodcock et al., 2000; Mackenzie et al., 2002; Li et al., 2005).
Previously, we reported that in mouse SAN, there is a substantial sarcolemmal $\mathrm{Ca}^{2+}$ influx upon $\mathrm{SR} \mathrm{Ca}^{2+}$ store depletion, a phenomenon known as "store-operated $\mathrm{Ca}^{2+}$ entry" (SOCE) (Ju et al., 2007; Ju and Allen, 2007). We also showed that type II IP ${ }_{3} \mathrm{R}$ are functionally expressed and affect $\mathrm{Ca}^{2+}$ handling and pacemaker activity in the mouse SAN and whose activation would lead to store depletion (Ju et al., 2011, 2012). The linkage between $\mathrm{IP}_{3} \mathrm{R}$ activation and SOCE has proven elusive, but a potential candidate, was found in HEK 293 cells expressing the Transient Receptor Potential Canonical-3 (TRPC3) channel (see below) (Kiselyov et al., 1998).

\section{TRPC3, SOCE/ROCE, and STIM1}

Studies on the transient receptor potential (TRP) gene from Drosophila showed that it encodes a PLC-activated $\mathrm{Ca}^{2+}$ permeable channel. Subsequently, seven homologs of TRP channels have been identified in mammals, termed TRPC1 to TRPC7 (Montell et al., 2002). TRPCs are thought to be strong candidates for the elusive SOCE pathway (for review see Salido et al., 2009). We have found that the SAN expresses all TRPC subtypes except TRPC5 (Ju et al., 2007). Among them, TRPC3 was the only subtype located in the surface membrane of pacemaker cells, making this isoform the strongest candidate for the SOCE channel in SAN (Ju et al., 2007).

$\mathrm{Ca}^{2+}$ influx can also be triggered as a direct consequence of PLC activation and production of diacylglycerol (DAG) that is independent of SR $\mathrm{Ca}^{2+}$ store depletion and forms a "receptoroperated $\mathrm{Ca}^{2+}$ entry" (ROCE) pathway (Mohl et al., 2011) (Figure 1). ROCE pathways may be closely related to SOCE

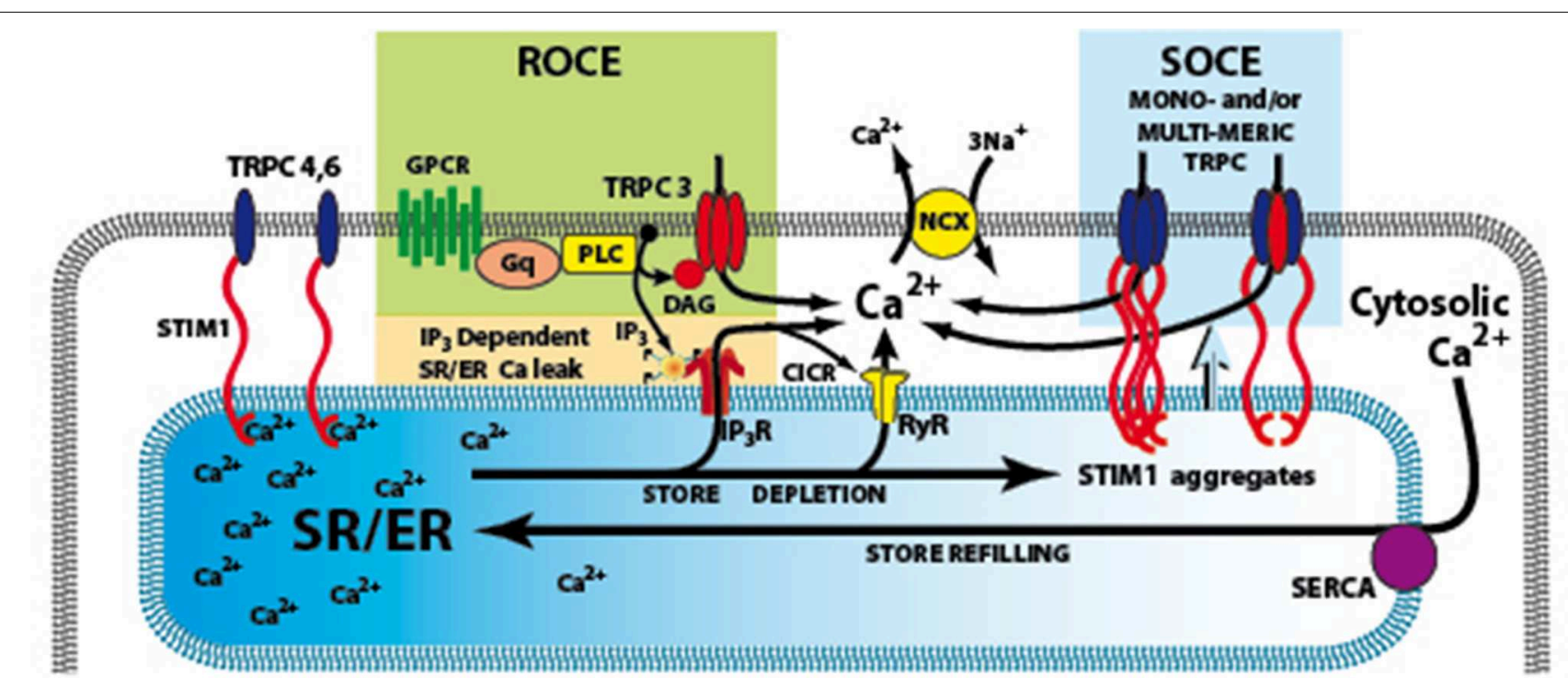

FIGURE 1 | Signaling pathways involved in the activation of TRPC3. The G-protein coupled receptor (GPCRs) activates phospholiase C (PLC), resulting in generation of IP3 and diacylglycerol (DAG). IP3 activates its receptor that leads to $\mathrm{Ca}^{2+}$ release from SR/ER and the depletion of $\mathrm{SR} / \mathrm{ER} \mathrm{Ca}^{2+}$ store. The $\mathrm{Ca}^{2+}$ content change in the store can be sensed by STIM1, the ER $\mathrm{Ca}^{2+}$ sensor and cause store-operated $\mathrm{Ca}^{2+}$ entry (SOCE) through TRPC3 channels. An additional or alternate possibility is that DAG can directly activate TRPC3, and produce receptor-operated $\mathrm{Ca}^{2+}$ entry (ROCE). GPCRs, G-protein coupled receptors; IP3R, inositol 1,4,5-trisphosphate receptors; PLC, Phospholipase C; ROCE, Receptor-operated $\mathrm{Ca}^{2+}$ entry; SOCE, store-operated $\mathrm{Ca}^{2+}$ entry; SR/ER, sarco- endo-plasmic reticulum; STIM1, stromal interacting molecule 1; TRPC3,4,6 canonical transient receptor potential channel types 3,4,6; NCX Na/Ca exchange. 
because PLC activation can be enhanced by $\mathrm{IP}_{3}$-induced store depletion. TRPC channels are non-selective $\mathrm{Ca}^{2+}$-permeable cation channels which are activated by diacylglycerol (DAG) liberated from the plasma membrane, triggered by agonist binding to $G$ protein-coupled receptors, such as angiotensin II and endothelin-1 receptors. Treatment with antisense RNA, to inhibit translation of endogenous TRPC 3 mRNA, reduces $\mathrm{Ca}^{2+}$ influx activated either by receptor stimulation or passive store depletion (Wu et al., 2004; Worley et al., 2007). Therefore, it is possible that TRPC3 is involved in both SOCE and ROCE (see Figure 1) (for review see Birnbaumer, 2009).

Another important breakthrough in SOCE/ROCE research was the identification of a new component of SOCE called stromal interacting molecule 1 (STIM1) (Roos et al., 2005). STIM1 functions as an ER/SR $\mathrm{Ca}^{2+}$ sensor, probably via a STIM1 $\mathrm{Ca}^{2+}$ binding $\mathrm{EF}$ hand inside the SR/ER lumen. The activation of SOCE requires STIM1 migration in the SR/ER membrane where it interacts with other molecular components of the SOCE system (Lewis, 2007). In addition, conformation coupling between $\mathrm{IP}_{3} \mathrm{R}$ and TRPC 3 has been suggested as a mechanism of activation of TRPC3 (Kiselyov et al., 1998) and a region in the $\mathrm{C}$ terminus of TRPC3 has been shown to interact with $\mathrm{IP}_{3}$ receptor as well as calmodulin (Calmodulin/ $\mathrm{IP}_{3}$ receptor-binding region (Zhang et al., 2001).

TRPC3 in cardiac cells provides a $\mathrm{Ca}^{2+}$ entry pathway that is connected to pathological signaling of the heart such as in cardiac hypertrophy (Onohara et al., 2006; Eder and Molkentin, 2011). However, there is little functional data on the role of TRPC3 in pacemaker and atrial cells to date. In the present study, we present new data suggesting that pacemaker cells expresses the molecular components of SOCE/ROCE pathways, including TRPC3, STIM1, and $\mathrm{IP}_{3} \mathrm{R} 2$. We present preliminary experiments using TRPC $3^{-/-}$mice and the specific TRPC3 channel blocker Pyr10 to show that TRPC3 appears to be able to contribute to sinoatrial and atrial arrhythmias induced by activation of GPCR $\mathrm{Ca}^{2+}$ signaling.

\section{Material and Methods}

\section{Animals}

Colonies of TRPC3 ${ }^{-/-}$mice (Hartmann et al., 2008) and their wild-type litter mates were gifts from Prof. Housley's laboratory at University of New South Wales. The mice were deeply anesthetised with intra peritoneal pentobarbitone $(1 \mathrm{ml} / 2 \mathrm{~kg})$ before any procedures were carried out. All procedures on mice were performed according to the guidelines of the National Health and Medical Research Council of Australia and approved by the Institutional Ethics Committee.

\section{Electrophysiological Studies in Langendorff-Perfused Hearts}

Hearts were cannulated and perfused with a modified Tyrode's solution containing (in $\mathrm{mM} / \mathrm{L}$ ) $130 \mathrm{NaCl}, 1.8 \mathrm{CaCl}_{2}, 1.2 \mathrm{MgCl}$, $5.4 \mathrm{KCl}, 1.2 \mathrm{NaH}_{2} \mathrm{PO}_{4}, 12 \mathrm{NaHCO}_{3}, 11$ glucose, 10 HEPES, with $\mathrm{pH}$ adjusted to 7.4 with $\mathrm{NaOH}$. Perfusion was set at a constant flow rate of $2-2.5 \mathrm{ml} / \mathrm{min}$ and solutions were oxygenated with $95 \% \mathrm{O}_{2}-5 \% \mathrm{CO}_{2}$. Electrical activity was recorded with two miniature monopolar ECG electrodes (Harvard Apparatus) placed on the atria and ventricle (Zhang et al., 2011). To determine the electrical conduction velocity of SAN and surrounding atrial tissue, custom-made electrode arrays were used to record the electrical activity from the isolated Langendorff-perfused hearts as described previously (Davies et al., 2014). To assess atrial arrhythmogenesis, Langendorff-perfused hearts from WT and $\mathrm{KO}$ mice were subjected to programmed electrical stimulation with three different pacing protocols as described elsewhere (Head et al., 2005; Zhang et al., 2011). Atrial tachycardia (AT) was defined as a sequence of three or more atrial depolarizations at the rate of $10 \mathrm{~Hz}$ or more than $10 \mathrm{~Hz}$. AF were characterized by irregular fibrillating waveforms. Sinus bradycardia was defined as a $30 \%$ reduction of baseline heart rate (HR) from the control condition. An arrhythmia index was calculated by the number of mice that have pacing induced arrhythmias events/the total number of mice in each group.

\section{The Preparation of Intact SAN and Single Pacemaker Cells}

Intact SANs were micro-dissected from right atria as described previously (Ju et al., 2007). The central SAN was identified from anatomical land marks, including the superior vena cava, the crista terminalis, and the interatrial septum (Marionneau et al., 2005). For physiological experiments, the intact SANs were continuously superfused with Tyrode's solution at $33^{\circ} \mathrm{C}$.

\section{Measurement of Intracellular $\mathrm{Ca}^{2+}$, SOCE and ROCE}

The isolated SANs were loaded with membrane-permeant fluorescent $\mathrm{Ca}^{2+}$ indicators, indo-1-AM or Fluo-4-AM $(10 \mu \mathrm{M} / \mathrm{L})$, using established methods (Ju and Allen, 1998; Ju et al., 2003). To measure $\mathrm{Ca}^{2+}$ influx through SOCE in sinoatrial tissue, preparations were exposed to a nominally $\mathrm{Ca}^{2+}$ free solution with the SR CaATPase pump inhibitor, cyclopiazonic acid (CPA, $10 \mu \mathrm{M})$ for $15 \mathrm{~min}$ to deplete the SR $\mathrm{Ca}^{2+}$ store. SOCE then occurs upon reintroduction of $\mathrm{Ca}^{2+}$ to the perfusate (Ju et al., 2007). ROCE was determined by measuring the agonist-mediated increases in $\left[\mathrm{Ca}^{2+}\right]_{\mathrm{i}}$ (Ang II, $1 \mu \mathrm{M} / \mathrm{L}$ and/or 1-oleoyl-2-acetyl-sn-glycerol OAG, $100 \mu \mathrm{M} / \mathrm{L}$ ) (Ikeda et al., 2013).

\section{Immunohistochemistry}

A rabbit polyclonal antibody was used to label type $\mathrm{II} \mathrm{IP}_{3} \mathrm{Rs}$ (1:200; Affinity Bioreagents) and TRPC3 (1:100, Alomone Lab) in single isolated pacemaker cells. A mouse antibody to STIM1 was also used (1:100, BD Biosciences). Anti-mouse or anti-rabbit secondary antibodies (Alexa-488 anti-mouse and Alexa-594 antirabbit (Molecular Probes) were used as secondary antibodies. Prolong gold antifade reagent with DAPI (Molecular Probes) was used as the mounting media and to provide nuclear staining.

\section{Osmotic Mini-Pump Implantation}

Alzet osmotic mini-pumps were implanted subcutaneously in $\mathrm{WT}$, or TRPC $3^{-/-}$mice. Ang II was delivered at the rate of $2 \mu \mathrm{g} / \mathrm{g} /$ day for $10-14$ days. 


\section{Statistics}

Data are expressed as mean \pm SEM, with the number of preparations as $n$. Statistical tests were either Student's paired or unpaired $t$-tests, and $P<0.05$ was used as the limit of statistical confidence.

\section{Results}

\section{Evidence for TRPC3 Involvment in Atrial Arrhythmias}

Ang II signaling pathways lead to a hypertrophy which seems to be related to TRPC3 expression (Onohara et al., 2006). To examine whether TRPC3 is involved in AF induced by Ang II, we induced AF in mice by pacing Langendorff-perfused hearts from WT and TRPC $3^{-/-}$KO mice which had been treated with Ang II (See Methods) over of 10-14 days. Figure 2A shows the conduction of the AP across the SAN to the atria reconstructed from the timing of the recorded electrical signals (panel below) using a 36 mini electrode array placed on the right atrium. Atrial arrhythmic events are illustrated in Figure $\mathbf{2 B}$, and were induced by using a pacing protocol that varied pacing voltage and frequency. To investigate the possible role of TRPC3 in these arrhythmias, we made ECG recordings from Langendorff-perfused hearts under control condition in $\mathrm{WT}$ and $\mathrm{TRPC} 3^{-/-}$respectively, as shown in the selected recordings illustrated in Figure 2C. Electrical pacing induced AF, AT, and conduction block were recorded and analyzed in WT and TRPC $3^{-/-}$, respectively (exemplar data shown in Figure 2D). We found that atrial arrhythmias induced by Ang II and pacing were significantly reduced in the TRPC $3^{-/-}$ mice compared to the controls $(P=0.004, n=11)$ (Figure 2E).

We previously reported that that pacemaker cells express TRPC3 and it is preferentially localized to the surface membrane (Ju et al., 2007). Therefore, the increased resistance to arrhythmias in TRPC3 ${ }^{-/}$mice supports the idea of a possible involvement of TRPC3 in arrhythmogenesis. As described above, $\mathrm{Ca}^{2+}$ entry through TRPC3 channel activated via a SOCE/ROCE signaling pathway and STIM1 could contribute arrhythmogenic current. To investigate this possibility, we examined expression and molecular localisation of STIM1, and the possibility of molecular interaction between TRPC 3 , STIM1, and $\mathrm{IP}_{3} \mathrm{R} 2$ in isolated cardiac pacemaker cells.

\section{Mouse Pacemaker Cells Express STIM1, a Molecular Component of SOCE /ROCE}

Previously, we demonstrated that mouse SAN tissue expressing HCN4 mRNA also expressed TRPC3 (Ju et al., 2007). We also found that pacemaker tissue express STIM1 mRNA and protein (Liu et al., 2015). In the present study we wanted to extend these findings to the localisation of TRPC3 and STIM1 in single isolated pacemaker cells. Figure 3 shows that isolated group (Figure 3A) and single pacemaker cells (Figure 1B) were positively labeled with a HCN4 antibody (which is a common selective molecular marker for pacemaker cells). The cells isolated from same SAN region were then double labeled with TRPC3 and STIM1 antibodies, and exemplar data is shown in Figure 3C. TRPC3 (red) showed both a sarcomeric pattern as well as membrane staining while STIM1 (green) displayed both cytosolic and near membrane labeling. A previous study examined the interaction of all mammalian TRPC channels with topically expressed STIM1 and found that that the STIM1 ERM domain binds to TRPC1, TRPC4, and TRPC5 but not TRPC3, TRPC6, and TRPC7 (Worley et al., 2007). However, knock down of STIM1 significantly reduced the current carried by TRPC3 (Yuan et al., 2007). The expression of both TRPC3 and STIM1 in cardiac pacemaker cells suggested to us that TRPC 3 could be involved in $\mathrm{Ca}^{2+}$ influx through SOCE.

We have previously reported that pacemaker cells express Type II $\mathrm{IP}_{3} \mathrm{R}\left(\mathrm{IP}_{3} \mathrm{R} 2\right)$ which can modulate pacemaker activity. To examine if $\mathrm{IP}_{3} \mathrm{R}$ and STIM1 form a signaling complex in SAN we double labeled isolated pacemaker cells with antiIP3R2 and anti-STIM1 antibodies. Figure 3D shows that STIM1 labeling occurred both in cell periphery as well as inside the cell. $I_{3} R 2$ was similarly distributed and there was some colocalization between these labels (yellow dots at the cell periphery in merged image). To achieve higher resolution $(\sim 100 \mathrm{~nm})$, a N-SIM/N-STORM super resolution microscope was used. Figure 3E shows the higher resolution N-SIM microscope image, which revealed tighter areas of co-localization between STIM1 and $\mathrm{IP}_{3} \mathrm{R} 2$. Given that the necessary molecular components of SOCE/ROCE (including TRPC3, and STIM1) as well as $\mathrm{IP}_{3} \mathrm{R}$ are present in pacemaker cells, we next examined if SOCE can be modulated by $\mathrm{IP}_{3} \mathrm{R}$ activation.

\section{Evidence for Interaction between $\mathrm{IP}_{3} \mathrm{Rs}$ and SOCE in Mouse Pacemaker Tissue}

To clarify if TRPC3 is involved in AF associated with GPCR activation (Figure 2), we examined whether SOCE /ROCE could be modified by GPCR activation. While we previously reported that enhanced $\mathrm{IP}_{3} \mathrm{R} \mathrm{Ca}^{2+}$ signaling modulated pacemaker firing rate, it remains unknown whether $\mathrm{IP}_{3} \mathrm{R}$ agonists and antagonists (which can modulate heart rate) also modulate SOCE activity in SAN. Previous work on cardiac myocytes showed that overexpression of TRPC3 enhanced $\mathrm{Ca}^{2+}$ entry through SOCE while knock down of TRPCs inhibited SOCE (Wu et al., 2010). We therefore used the intact mouse SAN preparation loaded with the ratiometric $\mathrm{Ca}^{2+}$ indicator indo-1 to study the interaction between $\mathrm{IP}_{3}$ Rs and SOCE.

After initial incubation of the SAN in $\mathrm{Ca}^{2+}$ free Tyrode's with the SR uptake blocked with CPA $(10 \mu \mathrm{mol} / \mathrm{L})$, reintroduction of $\mathrm{Ca}^{2+}(1.8 \mathrm{mmol} / \mathrm{L})$ caused a significant $\mathrm{Ca}^{2+}$ influx (i.e., SOCE) as shown by an increase in Indo- 1 ratio (Figure 4A). Importantly, peak SOCE was increased by $63 \pm 10 \%(n=4, P<0.05)$ in the presence of ET-1, a representative trace of which is shown in Figure 4A. Addition of the membrane permeant $\mathrm{IP}_{3}$ analog, $\mathrm{IP}_{3}-\mathrm{BM}(10 \mu \mathrm{mol} / \mathrm{L})$ was also able to increase SOCE by $31 \pm$ $10 \%$ ( $n=3$, data not shown). To test whether ET-1 or $\mathrm{IP}_{3}$ $\mathrm{BM}$ acted by opening $\mathrm{IP}_{3} \mathrm{R}$ release channels and thereby causing a greater store depletion (and hence SOCE), we examined the effect of enhancing store depletion by increasing both the CPA concentration and the incubation time in $\mathrm{Ca}^{2+}$ free solution. When the CPA concentration was increased from $10 \mu \mathrm{mol} / \mathrm{L}$ to $20 \mu \mathrm{mol} / \mathrm{L}$ and the incubation time in $\mathrm{Ca}^{2+}$ free buffer increased from $15 \mathrm{~min}$ to $30 \mathrm{~min}$ ET-1 was no longer able to further increase SOCE (Figure 4B). Similar results were found in three other 
A ms

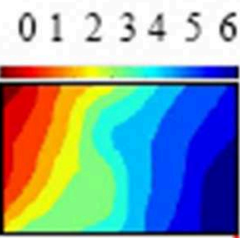

$\mathrm{ms}$
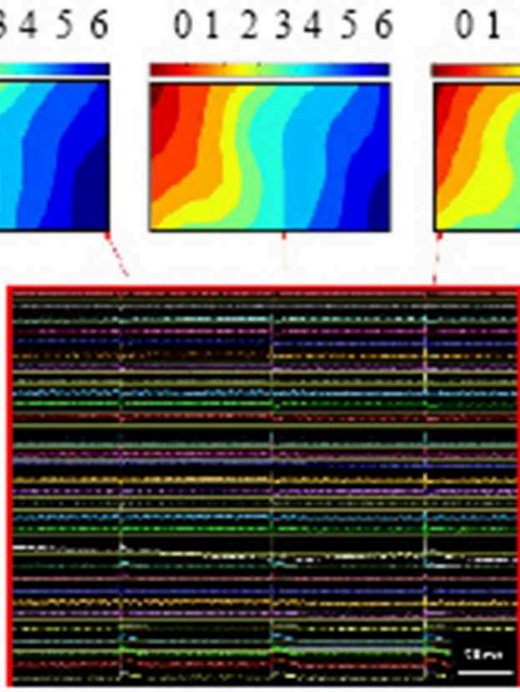

B

$\mathrm{ms}$

$\mathrm{ms}$

$\mathrm{ms}$

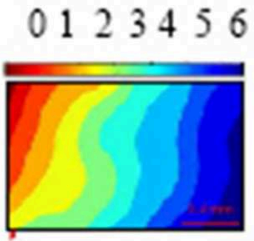

0123456012345601234560123456
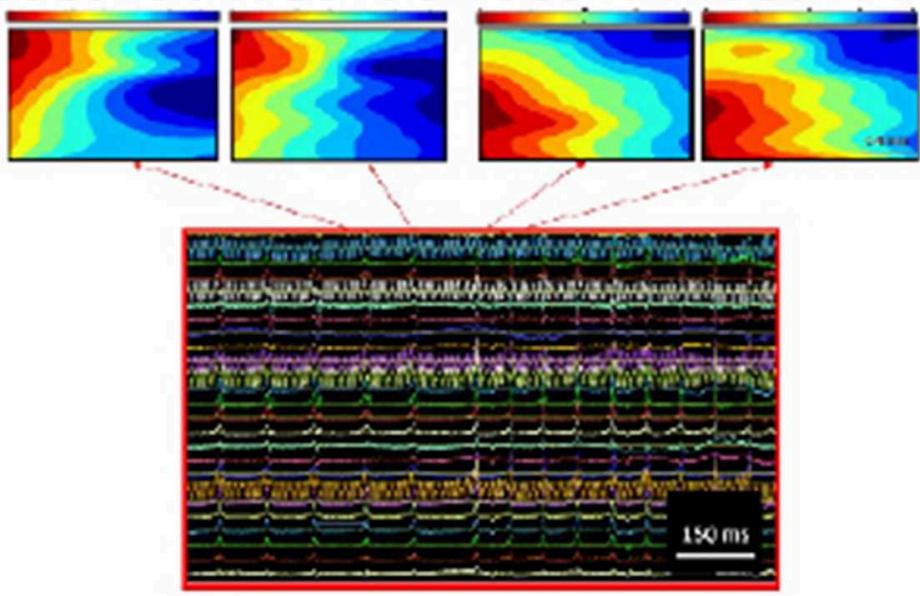

E

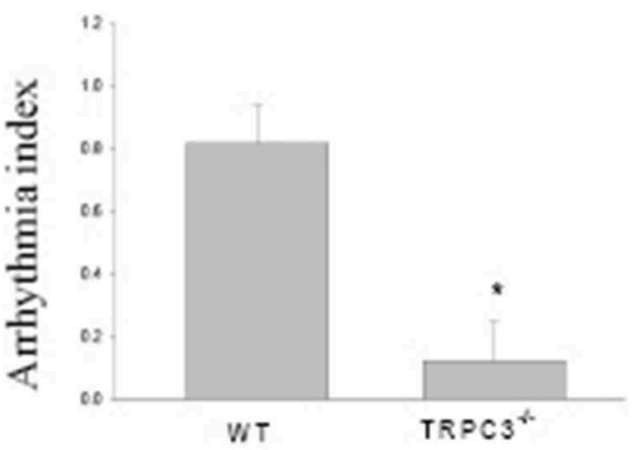

FIGURE 2 | Atrial arrhythmias induced by Ang II and pacing. Reconstructed excitation maps of data from multi-electrode array recordings (images below) from a Langendorff-perfused isolated heart. (A) sinus rhythm and (B) pacing induced atrial tachycardia. Note in AT, the ectopic beat starts from a different site to sinus rhythms. (C) Representative ECG recordings from isolated heart from WT and
C
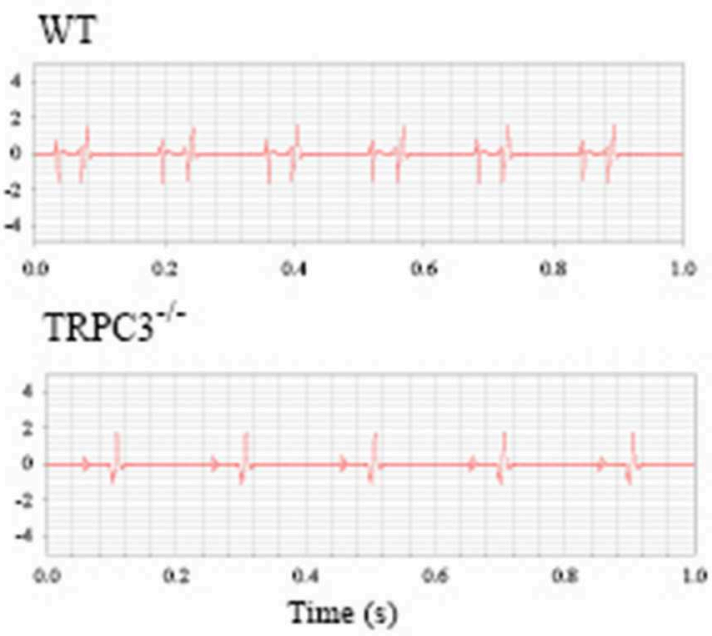

D WT
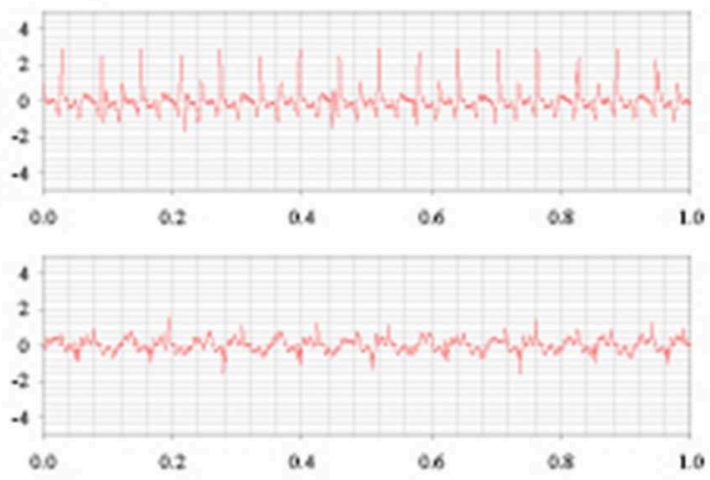

$\mathrm{TRPC}^{-1 /}$

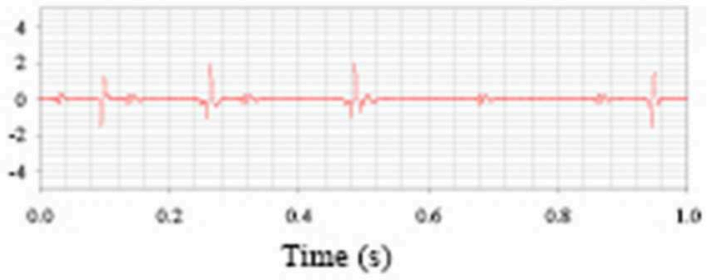

TRPC3 $-/-$ mice under control conditions. (D) Atrial tachycardia and atrial fibrillation induced by burst pacing in WT mice and atrial-ventricular conduction block recorded from a $\mathrm{TRPC}^{-/-}$mouse heart respectively. (E) On average, the arrhythmia index was significant reduced in TRPC3KO mice $(n=8)$ compared to WT mice $(n=11$, $P=0.004)$. 


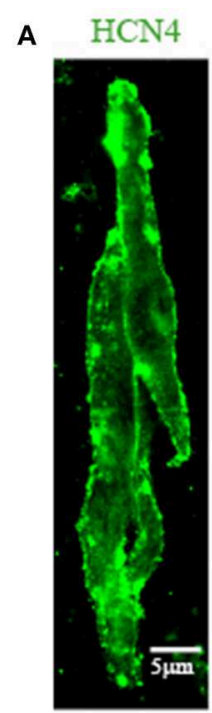

B

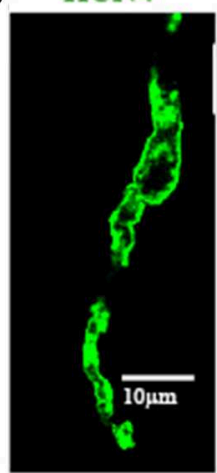

C
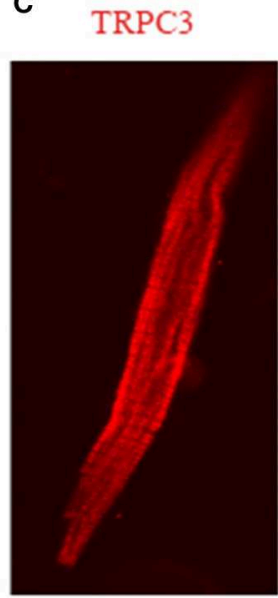

D $\quad \mathrm{IP}_{3} \mathrm{R} 2$

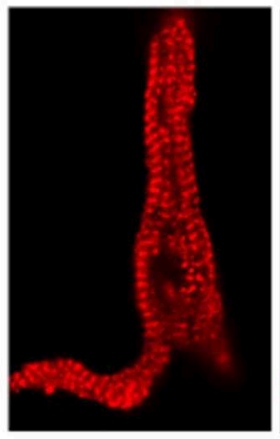

STIM1

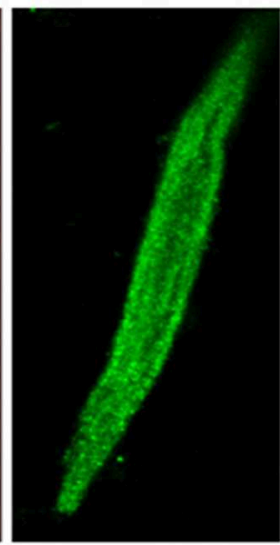

STIM1

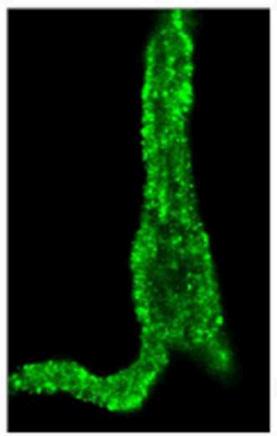

TRPC3/STIM1/DAPI

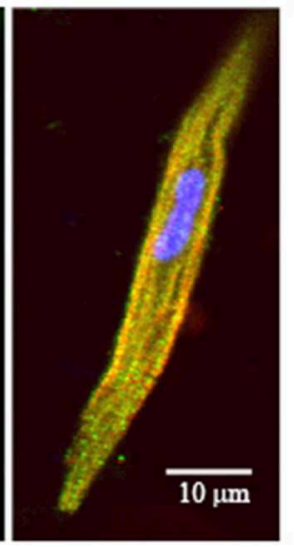

$\mathrm{IP}_{3} \mathrm{R} 2 / \mathrm{STIM} 1 / \mathrm{DAPI}$

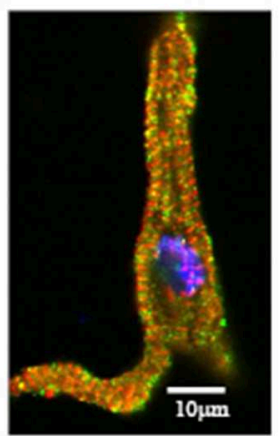

E

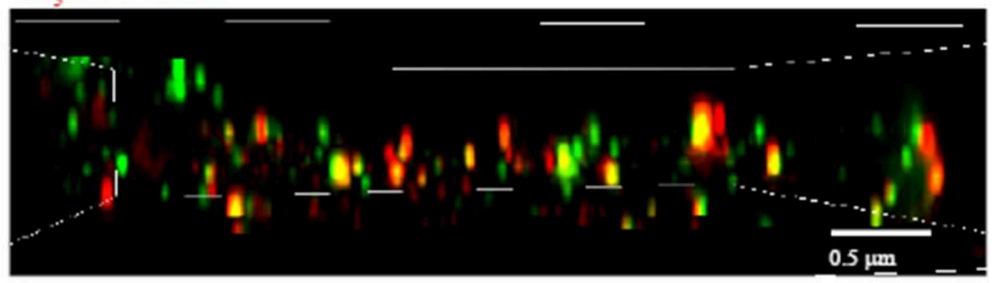

FIGURE 3 | Isolated single SAN cells express TRPC3, STIM1, and $\mathbf{I P}_{\mathbf{3}} \mathbf{R 2}$. Confocal immunofluorenscence images of isolated single pacemaker cells. Isolated group (A) and single (B) pacemaker cells were positively stained with anti HCN4 (in green). (C) Anti-TRPC3 in red, anti-STIM1 in green. (D) Anti-IP3R2 in red, anti-STIM1 in green. (E) $3 \mathrm{D}$ reconstruction image using $\mathrm{N}$-SIM microscopy. Anti-IP $\mathrm{P}_{3} \mathrm{R} 2$ in red, anti-STIM1 in green. Areas of co-localisation appear yellow due to color mixing.
SAN preparations. These results suggest that ET-1 exerts its effects on SOCE via activation of $\mathrm{IP}_{3} \mathrm{Rs}$ and caused $\mathrm{Ca}^{2+}$ release and store depletion rather than by direct stimulation of SOC channels.

Previous studies found that membrane permeant 2-APB has a direct effect on SOCE in some cell types, independent of its action as an $\mathrm{IP}_{3} \mathrm{R}$ antagonist.(Bootman et al., 2002) We tested this possibility by adding $40 \mu \mathrm{mol} / \mathrm{L} 2-\mathrm{APB}$ at the same time that $\mathrm{Ca}^{2+}$ was reintroduced to the solution (Figure 4C). $\mathrm{Ca}^{2+}$ influx through SOCE was not inhibited by 2 -APB under these conditions, suggesting that $2-\mathrm{APB}$ is not working as a direct SOCE channel blockers such as gadolinium or SKF-96365 (Ju et al., 2007). However, if 2-APB was added $15 \mathrm{~min}$ before reintroduction of $\mathrm{Ca}^{2+}, \mathrm{Ca}^{2+}$ entry via SOCE was then significantly inhibited (Figure 4D). On average, $\mathrm{Ca}^{2+}$ entry through the SOCE channel with 2 -APB decreased by $78 \pm 8 \%(n=4, P<0.01)$. Thus, 2-APB does not serve as a classic SOCE channel blocker in pacemaker cells, but can inhibit SOCE by a slower mechanism which may involve $\mathrm{IP}_{3} \mathrm{R} 2$ regulation as suggested previously (Ma et al., 2000). Although the specificity of 2-APB is questionable, we 

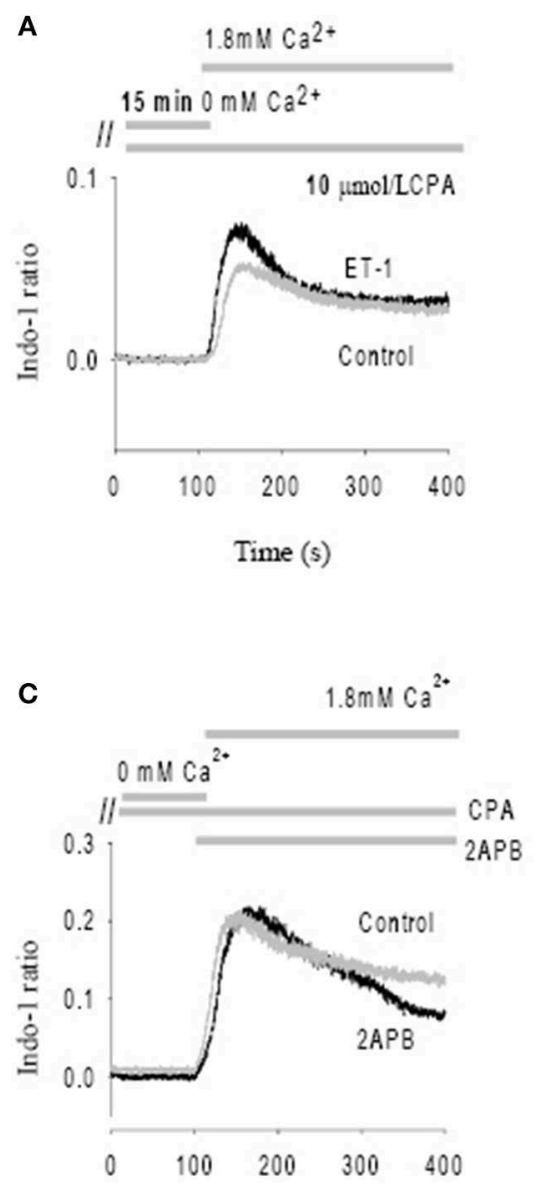

Time (s)

FIGURE 4 | Modulation of store-operated Ca entry (SOCE) by ET-1 and 2-APB. SOCE was induced by using cyclopiazonic acid (CPA) and low external $\mathrm{Ca}^{2+}$. The addition timing of extracellular $\mathrm{Ca}^{2+}$ change is indicated in the top panels. (A) The effect of ET-1 on SOCE induced by $10 \mu \mathrm{M}$ CPA with $15 \mathrm{~min}$ incubation in $\mathrm{Ca}^{2+}$ free Tyrode's solution. (B) The effect of ET-1 on SOCE induced by $20 \mu \mathrm{M}$ CPA with $30 \mathrm{~min}$ incubation in $\mathrm{Ca}^{2+}$ free Tyrode's solution. (C) The effect of $40 \mu \mathrm{M}$
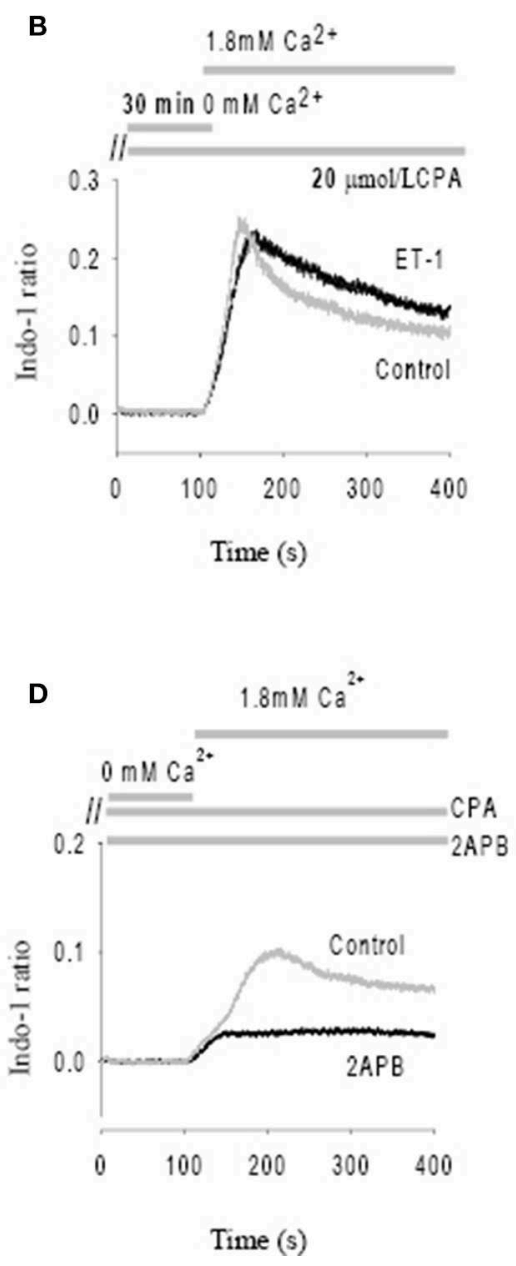

2-APB on SOCE. 2-APB was added in the same time of reintroduction of extracellular $\mathrm{Ca}^{2+}$ after perfusion of $\mathrm{Ca}^{2+}$ free Tyrode's Solution containing $10 \mu \mathrm{M}$ CPA. (D) The effect of $40 \mu \mathrm{M}$ 2-APB on SOCE. 2 -APB was added into the $\mathrm{Ca}^{2+}$ free Tyrode's solution with $10 \mu \mathrm{M}$ CPA during the $15 \mathrm{~min}$ incubation period. The gray traces represent controls; the black traces represent the treatments with ET-1 $(\mathbf{A}, \mathbf{B})$ or 2-APB (C,D), respectively. found that the effect of 2-APB was diminished in $\mathrm{IP}_{3} \mathrm{R} 2 \mathrm{KO}$, also supporting the involvement of $\mathrm{IP}_{3} \mathrm{R} 2$ in the slower onset effects of 2-APB on SOCE. These data are consistent with a previous study that suggested 2-APB blocks activation of TRPC3 indirectly via disruption of the coupling process between SOCE, TRPC and $\mathrm{IP}_{3} \mathrm{R}$ (Ma et al., 2002).

\section{Evidence TRPC3 is Involved in ROCE in Intact Mouse Sinoatrial Node}

TRPC3 has been implicated in not only SOCE but also ROCE (see Introduction) (for review see Birnbaumer, 2009). To further examine if $\mathrm{Ca}^{2+}$ influx through ROCE contributes to Ang II-induced arrhythmias we measured action potentials and $\mathrm{Ca}^{2+}$ influx in isolated SAN-atrial preparations treated with Ang II $(1 \mu \mathrm{M})$ and/or OAG $(100 \mu \mathrm{M})$, the agonists known to activate ROCE (Ikeda et al., 2013). Pyr3, a pyrazole derivative, has been suggested to be a blocker of TRPC3 (Kiyonaka et al., 2009) but it inhibits Orail mediated SOCE with similar potency (Salmon and Ahluwalia, 2010). Recently, a new selective blocker of TRPC3-ROCE blocker, Pyr10 has been developed and it displayed substantial selectivity for TRPC3-ROCE mediated responses over Orail mediated SOCE (Schleifer et al., 2012). We therefore studied the effect of Pyr10 on pacemaking and intracellular $\mathrm{Ca}^{2+}$ after application of Ang II and/or the DAG derivative, $\mathrm{OAG}$.

Figure 5 shows action potentials recorded from an intact sinoatrial node preparation using conventional intracellular recording techniques. After application of $1 \mu \mathrm{M}$ Ang II for $30 \mathrm{~min}$, there was an increase in pacemaker firing rate associated with a depolarised membrane potential (Figure 5B). Application of $2 \mu \mathrm{M}$ Pyr10 for $20 \mathrm{~min}$, slowed pacemaker firing rate 


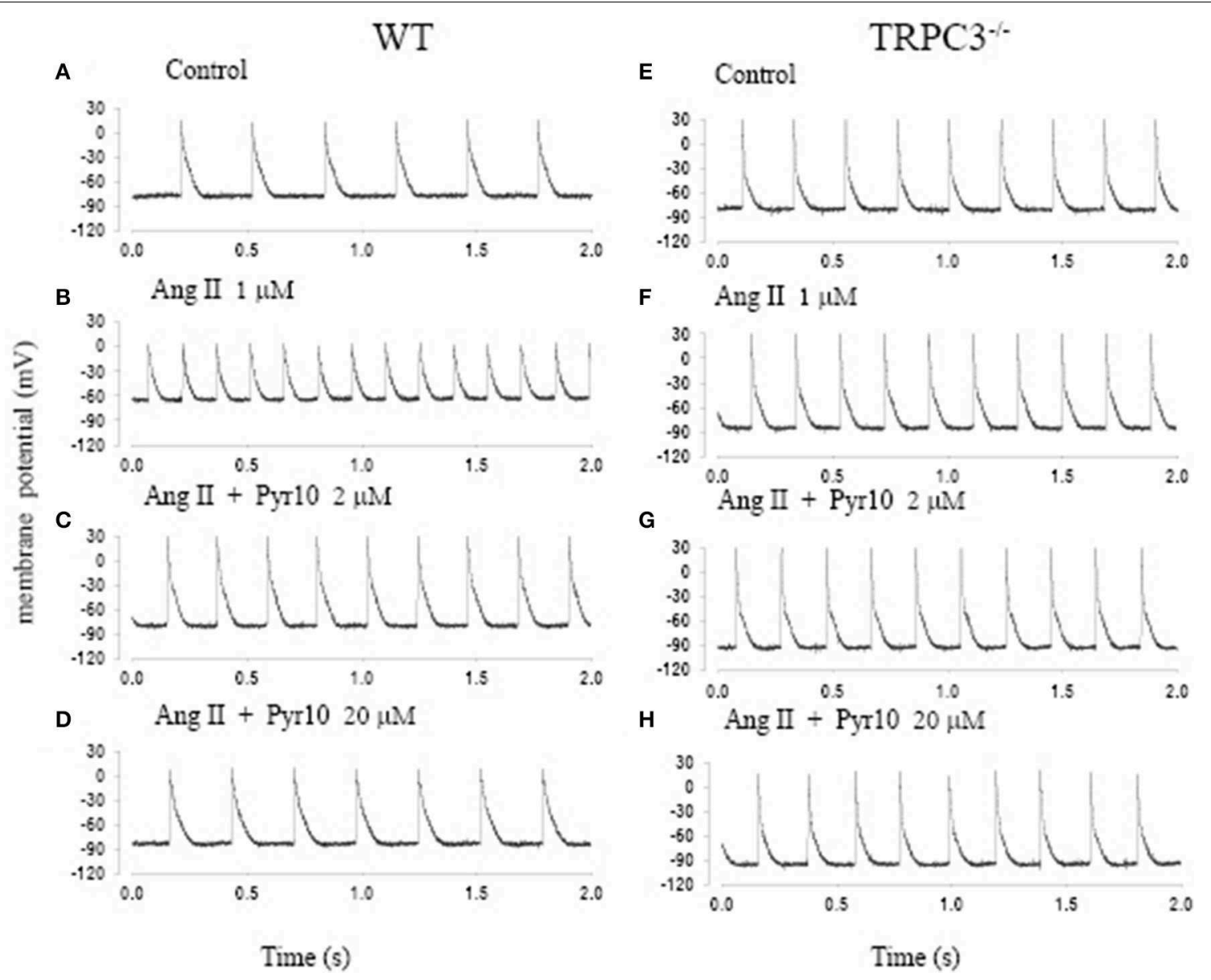

FIGURE 5 | The effect of angiotension II (Ang II) and a selective TRPC3 channel blocker Pyr10 on pacemaker action potential after application of Ang II. (A-D) Intracellular recordings from WT mice; (E-H) Intracellular recordings from TRPC3 ${ }^{-/}$- mice with conditions as indicated in each panel.

with maximum diastolic potential returning to the control level (Figure 5C). Application of $20 \mu \mathrm{M}$ Pyr10 further reduced firing rate within $7 \mathrm{~min}$ (Figure 5D). These results suggest that the membrane depolarization caused by Ang II could be reversed by the TRPC3 channel blocker. The results also support the idea that TRPC 3 could be a channel that produces an inward current after GPCR activation by Ang II (Onohara et al., 2006). Importantly, and in contrast to WT mice, the pacemaker firing rate and action potential depolarization were not affected by Ang II and this response not significantly altered by application of Pyr10 to SAN from TRPC3 KO mice (Figures 5E-H). This is consistent with pacing induced $\mathrm{AF}$ in mice treated with Ang II being reduced in TRPC $3^{-/-}$mice. (Figure 2) Therefore, these results strongly suggest that Pyr 10 not only specifically blocked TRPC 3 channels but that TRPC 3 also contributes to pacemaker activity. To further investigate if the changes in pacemaker activity were related to $\mathrm{Ca}^{2+}$ entry through ROCE we examined intracellular $\mathrm{Ca}^{2+}$ changes caused by OAG and the effect of Pyr10. Figure 6Aa shows a representative intracellular $\mathrm{Ca}^{2+}$ signal recorded from a WT intact sinoatrial preparation loaded with the $\mathrm{Ca}^{2+}$ indicator indo-1. Both resting $\mathrm{Ca}^{2+}$ and $\mathrm{Ca}^{2+}$ transients were increased after 20 min application of $100 \mu \mathrm{M}$ OAG (Figure 6Ab). Resting $\mathrm{Ca}^{2+}$ returned to the control level associated with a slowed firing rate after application of $2 \mu \mathrm{M}$ Pyr 10 for $15 \mathrm{~min}$ (Figure 6Ac). Further slowing and irregular pacemaker activity was apparent when the concentration of Pyr10 was increased to $20 \mu \mathrm{M}$ for $15 \mathrm{~min}$ as shown in Figure 6Ad. On average, resting $\mathrm{Ca}^{2+}$ increased by $20.2 \pm 6.9 \%(P=0.023, n=5)$; the $\mathrm{Ca}^{2+}$ transient also increased by $26.1 \pm 5.6 \%(p=0.003, n=5)$ and was associated with a $13.9 \%$ increase in pacemaker firing rate ( $p=0.005, n=5$,) in response to OAG treatment. There no significant changes by OAG in TRPC3 KO groups $(n=4)$ as shown in Figure 6B. The results further confirmed that TRPC3 was involved in OAG produced $\mathrm{Ca}^{2+}$ entry through ROCE upon GPCR activation. $2 \mu \mathrm{M}$ Pyr10 significantly reduced the resting $\mathrm{Ca}^{2+}$ elevation produced by OAG treatment in WT but not in TRPC3 KO mice (Figure 6C). Unexpectedly, PyR10 produced no significant changes in $\mathrm{Ca}^{2+}$ transient amplitude and firing rate in both groups after exposure to OAG. The results indicated that $\mathrm{Ca}^{2+}$ entry through ROCE appeared to mainly influence resting $\mathrm{Ca}^{2+}$ in pacemaker cells and the lack of effect of PYR10 after OAG stimulation on the $\mathrm{Ca}^{2+}$ transient and pacemaker firing 
rate may reflect additional effect(s) of PyR10 beyond TRPC3. In support of the latter idea, $20 \mu \mathrm{M}$ Pyr10 reduced the amplitude of the $\mathrm{Ca}^{2+}$ transient in TRPC3 KO mice without significantly changing pacemaker firing rate or resting $\mathrm{Ca}^{2+}$ level (data not show).

\section{Discussion}

\section{TRPC3 and Sino-Atrial Arrhythmias}

In this study, we found that pacing-induced atrial fibrillation in angiotensin II treated mice was significantly reduced in mice lacking the TRPC3 gene (TRPC3 ${ }^{-/-}$mice). This suggests that TRPC3 channels may be involved in Ang II induced changes in the electrical properties of sinoatrial tissue. Recent evidence has implicated $\mathrm{Ca}^{2+}$ entry through TRPC 3 as a pro-arrhythmic pathway (Harada et al., 2012). TRPC3 is known to be up-regulated in $\mathrm{AF}$ patients and experimental goat and canine AF models and also mediates a non-selective cation current in atrial fibroblasts (Harada et al., 2012). TRPC3 has also been implicated in dysfunction of SAN (Yanni et al., 2011) and atrioventricular conduction block (Sabourin et al., 2012). Collectively, all of these studies point to a functional role for TRPC3 activation in cardiac tissue and linkage to arrhythmogenesis.

Some ryrazole derivatives have recently been suggested to be relatively selective blockers for TRPC channels (Schleifer et al., 2012). In WT mice, we showed that Pyr10, blocked the membrane depolarization of SAN cause by Ang II and attenuated the increase in pacemaker firing rate induced by Ang II (Figure 5). A higher concentration of Pyr10 $(20 \mu \mathrm{M})$ induced slower and irregular pacemaker activity without changing the upstroke of the action potential (Figure 5D). The latter result suggests that Pyr10 did not block L-type Ca channels which provide the main cation current for the upstroke of pacemaker action potentials. (Irisawa et al., 1993) This effect of Pyr10 was similar to our previous observation using a different SOCE inhibitor (SKF-96365) (Ju et al., 2007). In contrast, Pyr10 did not cause any significant changes in slowing pacemaker action potentials recorded from sinoatrial tissue from TRPC3 $3^{-/-}$mice (Figure $5 \mathbf{H}$ ). These results suggest that Pyr 10 is mainly active on a SAN diastolic membrane current, and is in accord with the idea that TRPC 3 activation can provide a non-selective cation current in pacemaker cells (Eder and Molkentin, 2011). Intracellular $\mathrm{Ca}^{2+}$ measurements also showed that GPCR activation by Ang II or the DAG analog, OAG, caused an increase in both resting $\mathrm{Ca}^{2+}$ and $\mathrm{Ca}^{2+}$ transients that were associated with increased pacemaker firing rate in WT mice (Figure 6). The increased resting $\mathrm{Ca}^{2+}$ seemed directly related to ROCE as resting $\mathrm{Ca}^{2+}$ was significantly reduced in the presence of ROCE blocker, Pyr 10 (Figure 6C). In contrast, such changes were absent in the TRPC $3^{-/-}$group. These results provide further evidence that TRPC3 is involved in regulation of intracellular $\mathrm{Ca}^{2+}$ and ROCE mechanisms in SAN (Figure 6).

\section{Interaction between $\mathrm{IP}_{3} \mathrm{R}$ and SOCE in Cardiac Pacemaker Tissue}

It has become generally accepted that $\mathrm{Ca}^{2+}$ release from the SR contributes to pacemaker activity through its influence on NCX currents (Ju and Allen, 2001; Vinogradova et al., 2005; Maltsev and Lakatta, 2008). Alterations in $\mathrm{Ca}^{2+}$ metabolism and consequent changes in $\mathrm{Ca}^{2+}$ dependent currents (such as NCX) have also been implicated in failure of pacemaker function and cardiac arrhythmias (Du and Nathan, 2007; Maltsev and Lakatta, 2007).

We previously reported that $\mathrm{IP}_{3} \mathrm{Rs}$ are expressed in murine SAN and that the predominant isoform is the Type II $\mathrm{IP}_{3} \mathrm{R}$ $\left(\mathrm{IP}_{3} \mathrm{R} 2\right)$ (Ju et al., 2011). Importantly, the modulation of pacemaker firing and intracellular $\mathrm{Ca}^{2+}$ by $\mathrm{IP}_{3} \mathrm{R}$-agonists and antagonists was abolished in $\mathrm{IP}_{3} \mathrm{R} 2 \mathrm{KO}$ mice, demonstrating a clear functional, modulatory, role for $\mathrm{IP}_{3} \mathrm{R} 2$ in SAN. The present study also supports the idea that $\mathrm{Ca}^{2+}$ release via $\mathrm{IP}_{3} \mathrm{Rs}$ can modulate heart rate, depending on the activation of G-protein coupled receptors and the phospholipase $\mathrm{C}-\mathrm{IP}_{3}$ signaling pathway.

In non-excitable cells and smooth muscle, it has also been suggested that SOCE are coupled to $\mathrm{IP}_{3}$ Rs (Putney, 1986). Since the discovery of TRPC channels and their candidacy for the SOCE, interactions between $\mathrm{IP}_{3}$ Rs and members of the TRPC family have been reported (Vazquez et al., 2004). For example, it has been shown that $\mathrm{IP}_{3} \mathrm{R} 2$ interacts with TRPC 3 forming a protein complex that possibly underlies the enhanced SOCE activity seen in gravid uterine endothelium (Gifford et al., 2006). In the present study, we show that $\mathrm{Ca}^{2+}$ influx through SOCE in the SAN can be modulated by $\mathrm{IP}_{3}$ agonists(ET-1, IP $\left.{ }_{3}-\mathrm{BM}\right)$ and $\mathrm{IP}_{3} \mathrm{R} 2$ antagonists (2-APB) through mainly their effect on increasing $\mathrm{Ca}^{2+}$ release and hence reducing store content (see Figure 4). Since some $\mathrm{IP}_{3} \mathrm{Rs}$ appear to be localized near the surface membrane, where TRPC3 is also located (Ju et al., 2007, 2011), it is possible that $\mathrm{Ca}^{2+}$ release via $\mathrm{IP}_{3} \mathrm{Rs}$ could interact with these ion channels in the surface membrane (and/or affect their trafficking). $\mathrm{IP}_{3} \mathrm{R}$ expression has been shown to increase in heart failure (Marks, 2000) and in atrial fibrillation (Yamada et al., 2002), which raises the possibility that this IP3-TRPC signaling system may become more important in pathological conditions (Worley et al., 2007; Ju et al., 2012).

\section{SOCE over ROCE in Cardiac Tissue}

As described above, SOCE and ROCE may be linked phenomena but the extent to which these mechanisms cross-communicate/activate is unclear -especially after GPCR activation of PLC which triggers formation of $\mathrm{IP}_{3}$ and DAG (Liao et al., 2009). While it has been established that TRPC3 is involved in ROCE (Hofmann et al., 1999), it remains uncertain whether TRPC3 can also contribute to SOCE (for review see Cahalan, 2009) (Zagranichnaya et al., 2005; Dehaven et al., 2009).

We showed that TRPC3 expressing pacemaker cells also express the ${\mathrm{ER}-\mathrm{Ca}^{2+}}^{2+}$ sensor protein, STIM1. The latter may provide the missing molecular signaling link between $\mathrm{Ca}^{2+}$ release via $\mathrm{IP}_{3} \mathrm{Rs}$, store depletion and the activation of SOCE(Lewis, 2007; Yuan et al., 2007). However, it remains unclear whether STIM1 directly regulates the TRPC channels related to SOCE (Worley et al., 2007; Yuan et al., 2007; Dehaven et al., 2009). In addition to TRPCs, Orail is a protein that may produce a specific SOCE pathway and appears as a $\mathrm{Ca}^{2+}$ release activated $\mathrm{Ca}^{2+}$ current (Icrac). While we found that Orail is expressed in mouse pacemaker cells (not shown), TRPC3 was more dominant at both mRNA and protein levels (Ju et al., 2007). It has been suggested that TRPC 3 and Orail may form a complex that 

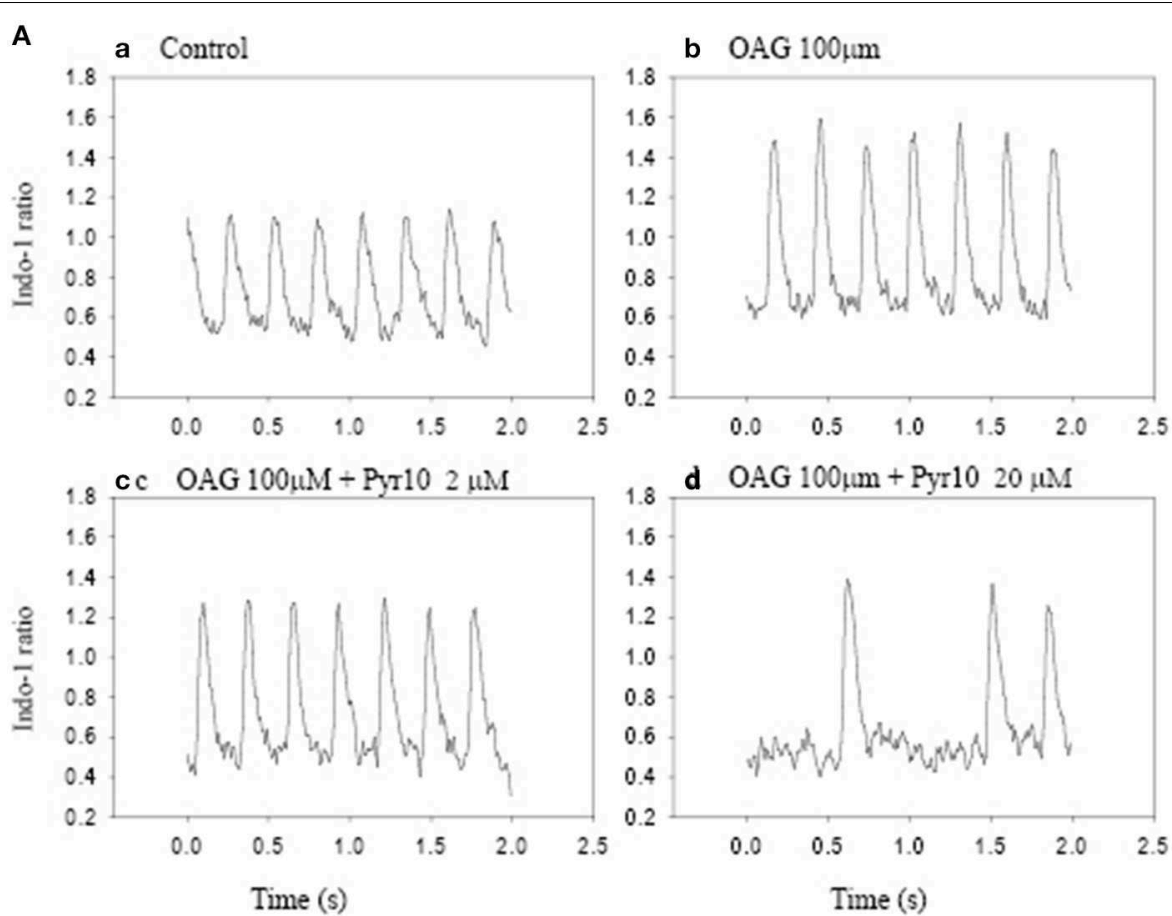

B

C
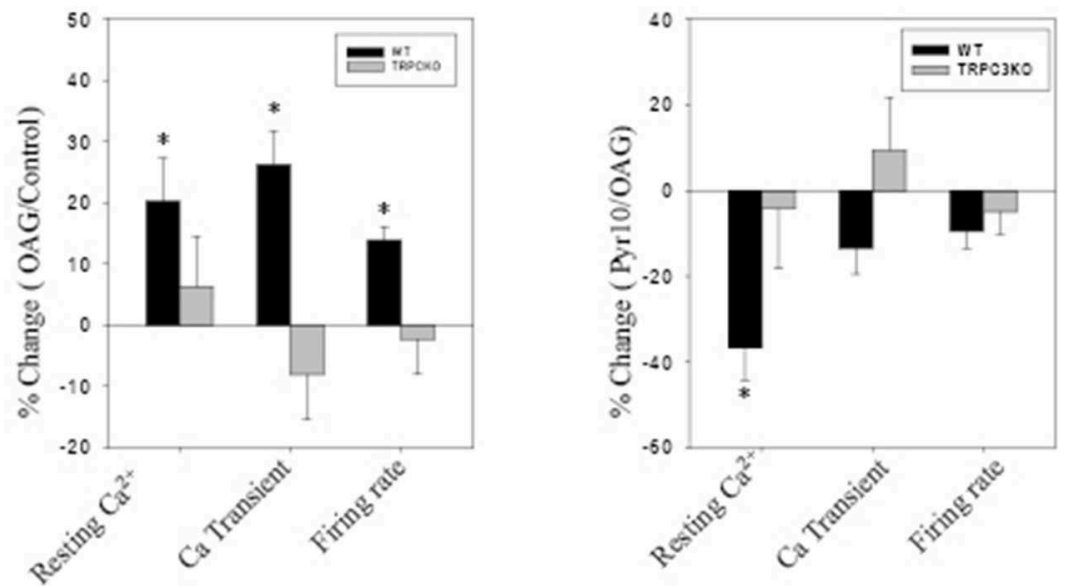

FIGURE 6 | The effect of Pyr10 on intracellular $\mathrm{Ca}^{2+}$ after application of 1-oleoy1-2-acyl-sn-glycerol (OAG) $100 \mu \mathrm{M}$. The intact SANs were loaded with $\mathrm{Ca}^{2+}$ indicator indo-1. (A,B) show intracellular $\mathrm{Ca}^{2+}$ recordings from a WT mouse. (B,C) The statistics pool data shows percentage changes in resting $\mathrm{Ca}^{2+}, \mathrm{Ca}^{2+}$ transient and firing rate in WT and TRPC3 $\mathrm{KO}$ mice respectively. (B) OAG treatment against control. (C) $2 \mu \mathrm{M}$ Pyr10 treatment against $\mathrm{OAG}$ treatment. ${ }^{*} P<0.05$. mediates both SOCE and ROCE and the conversion from ROCE to SOCE may be mediated through STIM1 binding (Liao et al., 2008).

\section{The Limitation of Current Study}

The current study does not rule out the possibility that Pyr10 has effects on currents other than TRPC3, such as $\mathrm{I}_{f}$. In addition, it would be desirable to examine if other molecular components, such as NCX, SERCA, etc. that regulate intracellular $\mathrm{Ca}^{2+}$ are changed in TRPC $3^{-/-}$mice. Despite these limitations, we shown that $\mathrm{Ca}^{2+}$ entry through both SOCE and ROCE occurs in murine
SAN and appears to be regulated by the GPCRs in a GPCR》 $\mathrm{PLC} \gg \mathrm{IP}_{3} \mathrm{R} / \mathrm{DAG} \gg \mathrm{Ca}^{2+}$ signal transduction cascade. We suggest that TRPC3 channels might provide a potential target for future treatment of SAN dysfunction and $\mathrm{AF}$ as it links both receptor activation and intracellular $\mathrm{Ca}^{2+}$ signaling.

\section{Acknowledgments}

This study was supported by the National Health and Medical Research Council of Australia (program grant 354400, and project grant 570926). 


\section{References}

Berridge, M. J. (2009). Inositol trisphosphate and calcium signalling mechanisms. Biochim. Biophys. Acta 1793, 933-940. doi: 10.1016/j.bbamcr.2008.10.005

Birnbaumer, L. (2009). The TRPC class of ion channels: a critical review of their roles in slow, sustained increases in intracellular $\mathrm{Ca}(2+)$ concentrations. Annu. Rev. Pharmacol. Toxicol. 49, 395-426. doi: 10.1146/annurev.pharmtox. 48.113006.094928

Bootman, M. D., Collins, T. J., Mackenzie, L., Roderick, H. L., Berridge, M. J., and Peppiatt, C. M. (2002). 2-aminoethoxydiphenyl borate (2-APB) is a reliable blocker of store- operated Ca2+ entry but an inconsistent inhibitor of InsP3induced Ca2+ release. FASEB J. 16, 1145-1150. doi: 10.1096/fj.02-0037rev

Cahalan, M. D. (2009). STIMulating store-operated Ca(2+) entry. Nat. Cell Biol. 11, 669-677. doi: 10.1038/ncb0609-669

Davies, L., Jin, J., Shen, W., Tsui, H., Shi, Y., Wang, Y., et al. (2014). Mkk4 is a negative regulator of the transforming growth factor beta 1 signaling associated with atrial remodeling and arrhythmogenesis with age. J. Am. Heart Assoc. 3:e000340. doi: 10.1161/JAHA.113.000340

Dehaven, W. I., Jones, B. F., Petranka, J. G., Smyth, J. T., Tomita, T., Bird, G. S., et al. (2009). TRPC channels function independently of STIM1 and Orail. J. Physiol. 587, 2275-2298. doi: 10.1113/jphysiol.2009.170431

Dobrev, D., and Nattel, S. (2008). Calcium handling abnormalities in atrial fibrillation as a target for innovative therapeutics. J. Cardiovasc. Pharmacol. 52, 293-299. doi: 10.1097/FJC.0b013e318171924d

Du, Y. M., and Nathan, R. D. (2007). Ionic basis of ischemia-induced bradycardia in the rabbit sinoatrial node. J. Mol. Cell. Cardiol. 42, 315-325. doi: 10.1016/j.yjmcc.2006.10.004

Duhme, N., Schweizer, P. A., Thomas, D., Becker, R., Schroter, J., Barends, T. R., et al. (2013). Altered HCN4 channel C-linker interaction is associated with familial tachycardia-bradycardia syndrome and atrial fibrillation. Eur. Heart J. 34, 2768-2775. doi: 10.1093/eurheartj/ehs391

Eder, P., and Molkentin, J. D. (2011). TRPC channels as effectors of cardiac hypertrophy. Circ. Res. 108, 265-272. doi: 10.1161/CIRCRESAHA.110.225888

Fedorov, V. V., Chang, R., Glukhov, A. V., Kostecki, G., Janks, D., Schuessler, R. B., et al. (2010). Complex interactions between the sinoatrial node and atrium during reentrant arrhythmias in the canine heart. Circulation 122, 782-789. doi: 10.1161/CIRCULATIONAHA.109.935288

Gifford, S. M., Yi, F. X., and Bird, I. M. (2006). Pregnancy-enhanced storeoperated $\mathrm{Ca} 2+$ channel function in uterine artery endothelial cells is associated with enhanced agonist-specific transient receptor potential channel 3-inositol 1,4,5-trisphosphate receptor 2 interaction. J. Endocrinol. 190, 385-395. doi: 10.1677/joe.1.06773

Greiser, M., Lederer, W. J., and Schotten, U. (2011). Alterations of atrial Ca(2+) handling as cause and consequence of atrial fibrillation. Cardiovasc. Res. 89, 722-733. doi: $10.1093 / \mathrm{cvr} / \mathrm{cvq} 389$

Harada, M., Luo, X., Qi, X. Y., Tadevosyan, A., Maguy, A., Ordog, B., et al. (2012). Transient receptor potential canonical-3 channel-dependent fibroblast regulation in atrial fibrillation. Circulation 126, 2051-2064. doi: 10.1161/CIRCULATIONAHA.112.121830

Hartmann, J., Dragicevic, E., Adelsberger, H., Henning, H. A., Sumser, M., Abramowitz, J., et al. (2008). TRPC3 channels are required for synaptic transmission and motor coordination. Neuron 59, 392-398. doi: 10.1016/j.neuron.2008.06.009

Head, C. E., Balasubramaniam, R., Thomas, G., Goddard, C. A., Lei, M., Colledge, W. H., et al. (2005). Paced electrogram fractionation analysis of arrhythmogenic tendency in DeltaKPQ Scn5a mice. J. Cardiovasc. Electrophysiol. 16, 1329-1340. doi: 10.1111/j.1540-8167.2005.00200.x

Hofmann, T., Obukhov, A. G., Schaefer, M., Harteneck, C., Gudermann, T., and Schultz, G. (1999). Direct activation of human TRPC6 and TRPC3 channels by diacylglycerol. Nature 397, 259-263. doi: 10.1038/16711

Hove-Madsen, L., Llach, A., Bayes-Genis, A., Roura, S., Rodriguez, F. E., Aris, A., et al. (2004). Atrial fibrillation is associated with increased spontaneous calcium release from the sarcoplasmic reticulum in human atrial myocytes. Circulation 110, 1358-1363. doi: 10.1161/01.CIR.0000141296.59 876.87

Ikeda, K., Nakajima, T., Yamamoto, Y., Takano, N., Tanaka, T., Kikuchi, H., et al. (2013). Roles of transient receptor potential canonical (TRPC) channels and reverse-mode $\mathrm{Na}+/ \mathrm{Ca} 2+$ exchanger on cell proliferation in human cardiac fibroblasts: effects of transforming growth factor beta1. Cell Calcium 54, 213-225. doi: 10.1016/j.ceca.2013.06.005

Irisawa, H., Brown, H. F., and Giles, W. (1993). Cardiac pacemaking in the sinoatrial node. Physiol. Rev. 73, 197-227.

Ju, Y. K., and Allen, D. G. (1998). Intracellular calcium and $\mathrm{Na}^{+}-\mathrm{Ca}^{2+}$ exchange current in isolated toad pacemaker cells. J. Physiol. 508, 153-166. doi: 10.1111/j.1469-7793.1998.153br.x

Ju, Y. K., and Allen, D. G. (2001). Does $\mathrm{Ca}^{2+}$ release from the sarcoplasmic reticulum influence heart rate? Clin. Exp. Pharmacol. Physiol. 28, 703-708. doi: 10.1046/j.1440-1681.2001.03506.x

Ju, Y. K., and Allen, D. G. (2007). Store-operated Ca2+ entry and TRPC expression; possible roles in cardiac pacemaker tissue. Heart Lung Circ. 16, 349-355. doi: 10.1016/j.hlc.2007.07.004

Ju, Y. K., Chu, Y., Chaulet, H., Lai, D., Gervasio, O. L., Graham, R. M., et al. (2007). Store-operated $\mathrm{Ca}^{2+}$ influx and expression of TRPC genes in mouse sinoatrial node. Circ. Res. 100, 1605-1614. doi: 10.1161/CIRCRESAHA.107.152181

Ju, Y. K., Huang, W. B., Jiang, L., Barden, J. A., and Allen, D. G. (2003). ATP modulates intracellular $\mathrm{Ca}^{2+}$ and firing rate through a $\mathrm{P} 2 \mathrm{Y} 1$ purinoceptor in cane toad pacemaker cells. J. Physiol. 552, 777-787. doi: 10.1113/jphysiol.2003.052258

Ju, Y. K., Liu, J., Lee, B. H., Lai, D., Woodcock, E. A., Lei, M., et al. (2011) Distribution and functional role of inositol 1,4,5-trisphosphate receptors in mouse sinoatrial node. Circ. Res. 109, 848-857. doi: 10.1161/CIRCRESAHA.111.243824

Ju, Y. K., Woodcock, E. A., Allen, D. G., and Cannell, M. B. (2012). Inositol 1,4,5-trisphosphate receptors and pacemaker rhythms. J. Mol. Cell. Cardiol. 53, 375-381. doi: 10.1016/j.yjmcc.2012.06.004

Kiselyov, K., Xu, X., Mozhayeva, G., Kuo, T., Pessah, I., Mignery, G., et al. (1998). Functional interaction between InsP3 receptors and store-operated Htrp3 channels. Nature 396, 478-482. doi: 10.1038/24890

Kiyonaka, S., Kato, K., Nishida, M., Mio, K., Numaga, T., Sawaguchi, Y., et al. (2009). Selective and direct inhibition of TRPC3 channels underlies biological activities of a pyrazole compound. Proc. Natl. Acad. Sci. U.S.A. 106, 5400-5405. doi: $10.1073 /$ pnas.0808793106

Lewis, R. S. (2007). The molecular choreography of a store-operated calcium channel. Nature 446, 284-287. doi: 10.1038/nature05637

Li, X., Zima, A. V., Sheikh, F., Blatter, L. A., and Chen, J. (2005). Endothelin1 -induced arrhythmogenic $\mathrm{Ca} 2+$ signaling is abolished in atrial myocytes of inositol-1,4,5-trisphosphate(IP3)-receptor type 2-deficient mice. Circ. Res. 96, 1274-1281. doi: 10.1161/01.RES.0000172556.05576.4c

Liao, Y., Erxleben, C., Abramowitz, J., Flockerzi, V., Zhu, M. X., Armstrong, D. L., et al. (2008). Functional interactions among Orail, TRPCs, and STIM1 suggest a STIM-regulated heteromeric Orai/TRPC model for SOCE/Icrac channels. Proc. Natl. Acad. Sci. U.S.A. 105, 2895-2900. doi: 10.1073/pnas.0712288105

Liao, Y., Plummer, N. W., George, M. D., Abramowitz, J., Zhu, M. X., and Birnbaumer, L. (2009). A role for Orai in TRPC-mediated Ca2+ entry suggests that a TRPC:Orai complex may mediate store and receptor operated Ca2+ entry. Proc. Natl. Acad. Sci. U.S.A. 106, 3202-3206. doi: 10.1073/pnas.0813 346106

Liu, J., Xin, L., Benson, V. L., Allen, D. G., and Ju, Y.-K. (2015). Store-operated calcium entry and the localization of STIM1 and Orail proteins in isolated mouse sinoatrial node cells. Front. Physiol. 6:69. doi: 10.3389/fphys.2015.00069

Ma, H. T., Patterson, R. L., van Rossum, D. B., Birnbaumer, L., Mikoshiba, K., and Gill, D. L. (2000). Requirement of the inositol trisphosphate receptor for activation of store-operated Ca2+ channels. Science 287, 1647-1651. doi: $10.1126 /$ science.287.5458.1647

Ma, H. T., Venkatachalam, K., Parys, J. B., and Gill, D. L. (2002). Modification of store-operated channel coupling and inositol trisphosphate receptor function by 2 -aminoethoxydiphenyl borate in DT40 lymphocytes. J. Biol. Chem. 277, 6915-6922. doi: 10.1074/jbc.M107755200

Mackenzie, L., Bootman, M. D., Laine, M., Berridge, M. J., Thuring, J., Holmes, A., et al. (2002). The role of inositol 1,4,5-trisphosphate receptors in $\mathrm{Ca}^{2+}$ signalling and the generation of arrhythmias in rat atrial myocytes. J. Physiol. 541, 395-409. doi: 10.1113/jphysiol.2001.013411

Maltsev, V. A., and Lakatta, E. G. (2007). Cardiac pacemaker cell failure with preserved $\mathrm{I}(\mathrm{f}), \mathrm{I}(\mathrm{CaL})$, and $\mathrm{I}(\mathrm{Kr})$ : a lesson about pacemaker function learned from ischemia-induced bradycardia. J. Mol. Cell. Cardiol. 42, 289-294. doi: 10.1016/j.yjmcc.2006.11.009 
Maltsev, V. A., and Lakatta, E. G. (2008). Dynamic interactions of an intracellular $\mathrm{Ca}^{2+}$ clock and membrane ion channel clock underlie robust initiation and regulation of cardiac pacemaker function. Cardiovasc. Res. 77, 274-284. doi: $10.1093 / \mathrm{cvr} / \mathrm{cvm} 058$

Marionneau, C., Couette, B., Liu, J., Li, H., Mangoni, M. E., Nargeot, J., et al. (2005). Specific pattern of ionic channel gene expression associated with pacemaker activity in the mouse heart. J. Physiol. 562, 223-234. doi: 10.1113/jphysiol.2004.074047

Marks, A. R. (2000). Cardiac intracellular calcium release channels-role in heart failure. Circ. Res. 87, 8-11. doi: 10.1161/01.RES.87.1.8

Mohl, M. C., Iismaa, S. E., Xiao, X. H., Friedrich, O., Wagner, S., NikolovaKrstevski, V., et al. (2011). Regulation of murine cardiac contractility by activation of alpha(1A)-adrenergic receptor-operated $\mathrm{Ca}(2+)$ entry. Cardiovasc. Res. 91, 310-319. doi: 10.1093/cvr/cvr081

Montell, C., Birnbaumer, L., and Flockerzi, V. (2002). The TRP channels, a remarkably functional family. Cell 108, 595-598. doi: 10.1016/S0092-8674(02)00670-0

Nattel, S. (2002). New ideas about atrial fibrillation 50 years on. Nature 415, 219-226. doi: 10.1038/415219a

Neef, S., Dybkova, N., Sossalla, S., Ort, K. R., Fluschnik, N., Neumann, K., et al. (2010). CaMKII-dependent diastolic SR Ca2+ leak and elevated diastolic Ca2+ levels in right atrial myocardium of patients with atrial fibrillation. Circ. Res. 106, 1134-1144. doi: 10.1161/CIRCRESAHA.109.203836

Onohara, N., Nishida, M., Inoue, R., Kobayashi, H., Sumimoto, H., Sato, Y., et al. (2006). TRPC3 and TRPC6 are essential for angiotensin II-induced cardiac hypertrophy. EMBO J. 25, 5305-5316. doi: 10.1038/sj.emboj.7601417

Putney, J. W. Jr. (1986). A model for receptor-regulated calcium entry. Cell Calcium 7, 1-12. doi: 10.1016/0143-4160(86)90026-6

Roos, J., DiGregorio, P. J., Yeromin, A. V., Ohlsen, K., Lioudyno, M., Zhang, S., et al. (2005). STIM1, an essential and conserved component of store-operated Ca2+ channel function. J. Cell Biol. 169, 435-445. doi: 10.1083/jcb.200502019

Sabourin, J., Antigny, F., Robin, E., Frieden, M., and Raddatz, E. (2012). Activation of transient receptor potential canonical 3 (TRPC3)-mediated Ca2+ entry by A1 adenosine receptor in cardiomyocytes disturbs atrioventricular conduction. J. Biol. Chem. 287, 26688-26701. doi: 10.1074/jbc.M112.378588

Salido, G. M., Sage, S. O., and Rosado, J. A. (2009). TRPC channels and store-operated $\mathrm{Ca}(2+)$ entry. Biochim. Biophys. Acta 1793, 223-230. doi: 10.1016/j.bbamcr.2008.11.001

Salmon, M. D., and Ahluwalia, J. (2010). Discrimination between receptor- and store-operated $\mathrm{Ca}(2+)$ influx in human neutrophils. Cell. Immunol. 265, 1-5. doi: 10.1016/j.cellimm.2010.07.009

Sanders, P., Morton, J. B., Kistler, P. M., Spence, S. J., Davidson, N. C., Hussin, A., et al. (2004). Electrophysiological and electroanatomic characterization of the atria in sinus node disease: evidence of diffuse atrial remodeling. Circulation 109, 1514-1522. doi: 10.1161/01.CIR.0000121734.47409.AA

Schleifer, H., Doleschal, B., Lichtenegger, M., Oppenrieder, R., Derler, I., Frischauf, I., et al. (2012). Novel pyrazole compounds for pharmacological discrimination between receptor-operated and store-operated $\mathrm{Ca}(2+)$ entry pathways. $\mathrm{Br}$. J. Pharmacol. 167, 1712-1722. doi: 10.1111/j.1476-5381.2012.02126.x

Sipido, K. R., Varro, A., and Eisner, D. (2006). Sodium calcium exchange as a target for antiarrhythmic therapy. Handb. Exp. Pharmacol. 159-199. doi: 10.1007/3-540-29715-4_6

Vazquez, G., Wedel, B. J., Aziz, O., Trebak, M., and Putney, J. W. Jr. (2004). The mammalian TRPC cation channels. Biochim. Biophys. Acta 1742, 21-36. doi: 10.1016/j.bbamcr.2004.08.015

Vest, J. A., Wehrens, X. H., Reiken, S. R., Lehnart, S. E., Dobrev, D., Chandra, P., et al. (2005). Defective cardiac ryanodine receptor regulation during atrial fibrillation. Circulation 111, 2025-2032. doi: 10.1161/01.CIR.0000162461.67140.4C
Vinogradova, T. M., Maltsev, V. A., Bogdanov, K. Y., Lyashkov, A. E., and Lakatta, E. G. (2005). Rhythmic $\mathrm{Ca}^{2+}$ oscillations drive sinoatrial nodal cell pacemaker function to make the heart tick. Ann. N.Y. Acad. Sci. 1047, 138-156. doi: 10.1196/annals.1341.013

Wakili, R., Voigt, N., Kaab, S., Dobrev, D., and Nattel, S. (2011). Recent advances in the molecular pathophysiology of atrial fibrillation. J. Clin. Invest. 121, 2955-2968. doi: 10.1172/JCI46315

Woodcock, E. A., Arthur, J. F., and Matkovich, S. J. (2000). Inositol 1,4,5trisphosphate and reperfusion arrhythmias. Clin. Exp. Pharmacol. Physiol. 27, 734-737. doi: 10.1046/j.1440-1681.2000.03328.x

Worley, P. F., Zeng, W., Huang, G. N., Yuan, J. P., Kim, J. Y., Lee, M. G., et al. (2007). TRPC channels as STIM1-regulated store-operated channels. Cell Calcium 42, 205-211. doi: 10.1016/j.ceca.2007.03.004

Wu, X., Eder, P., Chang, B., and Molkentin, J. D. (2010). TRPC channels are necessary mediators of pathologic cardiac hypertrophy. Proc. Natl. Acad. Sci. U.S.A. 107, 7000-7005. doi: 10.1073/pnas.1001825107

Wu, X., Zagranichnaya, T. K., Gurda, G. T., Eves, E. M., and Villereal, M. L. (2004). A TRPC1/TRPC3-mediated increase in store-operated calcium entry is required for differentiation of H19-7 hippocampal neuronal cells. J. Biol. Chem. 279, 43392-43402. doi: 10.1074/jbc.M408959200

Yamada, J., Ohkusa, T., Nao, T., Ueyama, T., Yano, M., Kobayashi, S., et al. (2002). [Up-regulation of inositol 1, 4, 5-trisphosphate receptor expression in atrial tissue in patients with chronic atrial fibrillation]. J. Cardiol. 39, 57-58. doi: 10.1016/S0735-1097(01)01144-5

Yanni, J., Tellez, J. O., Maczewski, M., Mackiewicz, U., Beresewicz, A., Billeter, R., et al. (2011). Changes in ion channel gene expression underlying heart failure-induced sinoatrial node dysfunction. Circ. Heart Fail. 4, 496-508. doi: 10.1161/CIRCHEARTFAILURE.110.957647

Yeh, Y. H., Wakili, R., Qi, X. Y., Chartier, D., Boknik, P., Kaab, S., et al. (2008). Calcium-handling abnormalities underlying atrial arrhythmogenesis and contractile dysfunction in dogs with congestive heart failure. Circ. Arrhythm. Electrophysiol. 1, 93-102. doi: 10.1161/CIRCEP.107.754788

Yuan, J. P., Zeng, W., Huang, G. N., Worley, P. F., and Muallem, S. (2007) STIM1 heteromultimerizes TRPC channels to determine their function as store-operated channels. Nat. Cell Biol. 9, 636-645. doi: 10.1038/ncb1590

Zagranichnaya, T. K., Wu, X., and Villereal, M. L. (2005). Endogenous TRPC1, TRPC3, and TRPC7 proteins combine to form native storeoperated channels in HEK-293 cells. J. Biol. Chem. 280, 29559-29569. doi: 10.1074/jbc.M505842200

Zhang, Y., Fraser, J. A., Jeevaratnam, K., Hao, X., Hothi, S. S., Grace, A. A., et al. (2011). Acute atrial arrhythmogenicity and altered $\mathrm{Ca}(2+)$ homeostasis in murine RyR2-P2328S hearts. Cardiovasc. Res. 89, 794-804. doi: $10.1093 / \mathrm{cvr} / \mathrm{cvq} 229$

Zhang, Z., Tang, J., Tikunova, S., Johnson, J. D., Chen, Z., Qin, N., et al. (2001). Activation of Trp3 by inositol 1,4,5-trisphosphate receptors through displacement of inhibitory calmodulin from a common binding domain. Proc. Natl. Acad. Sci. U.S.A. 98, 3168-3173. doi: 10.1073/pnas.051632698

Conflict of Interest Statement: The authors declare that the research was conducted in the absence of any commercial or financial relationships that could be construed as a potential conflict of interest.

Copyright (c) 2015 Ju, Lee, Trajanovska, Hao, Allen, Lei and Cannell. This is an open-access article distributed under the terms of the Creative Commons Attribution License (CC BY). The use, distribution or reproduction in other forums is permitted, provided the original author(s) or licensor are credited and that the original publication in this journal is cited, in accordance with accepted academic practice. No use, distribution or reproduction is permitted which does not comply with these terms. 